\title{
Staffing levels at KwaZulu-Natal district hospitals: is the University of KwaZulu-Natal training for the needs of the province?
}

\author{
Andrew Ross ${ }^{a *}$, Dumsani Gumede ${ }^{\mathrm{b}}$ and Solange Mianda ${ }^{\mathrm{ac}}$ \\ a Department of Family Medicine, University of KwaZulu-Natal, Durban, South Africa \\ 'Umthombo Youth Development Foundation, Durban, South Africa \\ cPublic Health Medicine, University of KwaZulu-Natal, Durban, South Africa \\ *Corresponding author, email: rossa@ukzn.ac.za
}

Background: Universities have a social responsibility to ensure that they select and train healthcare professionals (HCPs) who can meet the healthcare needs of local communities. The aim of this study was to assess the extent to which the University of KwaZulu-Natal (UKZN) contributes to the training of HCPs working in district hospitals (DHs) in KwaZulu-Natal Province, and the impact that the funding source for their training has on DH staffing.

Methods: This was an observational descriptive study, with all doctors, dentists, dental therapists, pharmacists, physiotherapists and radiographers working at DHs in KZN in November 2016 being invited to participate. Data were collected through a validated questionnaire.

Results: A total of $514 \mathrm{HCPs}$ working in $29 \mathrm{DHs}$ participated in the study; over half (57\%) of the South African medical graduates had trained at UKZN, as had $62 \%$ of pharmacists, $64 \%$ of physiotherapists and $92 \%$ of dental therapists. Some $87 \%$ of the HCPs had worked in DHs for five years or less, 65\% planned to leave in the near future, and 29\% planned to leave at the end of 2016. Discussion: UKZN plays a significant role in training for the short-term needs of DHs in KZN. Much of the workforce is young and transient, which has implications for service provision and expanding the teaching platform to DHs. The lack of long-term staff retention suggests that UKZN needs to continually monitor the selection of students, as well as the content and context of the training, if it is to contribute to the province's long-term staffing needs.

Keywords: district hospitals, KwaZulu-Natal, professional staffing levels, training

\section{Background}

South Africa (SA) is characterised by the inequitable distribution of healthcare professionals (HCPs) and services. ${ }^{1}$ Most doctors prefer to work in the private sector, resulting in $85 \%$ of the population having to rely on the under-resourced public health sector. ${ }^{2}$ In addition to the challenges caused by the publicprivate divide, only $12 \%$ of South African doctors work in rural areas, in which $44 \%$ of the population live. ${ }^{3,4}$ Staffing public healthcare facilities in SA is thus an ongoing challenge, with many rural areas experiencing considerable staff shortages. ${ }^{5,6}$

The South African National Development Plan $2013^{7}$ and Human Resources for Health 2030 strategy $^{3}$ tasked Institutions of Higher Learning $(\mathrm{IHL})$ with training an increasing numbers of HCPs as a key component to ensuring a 'long and healthy life for all South Africans.' These documents highlight the need for IHL to develop plans to ensure that adequate number of HCPs are trained to address the needs of all South Africans, including those living in rural and underserved communities.

Although local and international evidence shows that ruralorigin students are more likely to work in rural areas, ${ }^{8-10}$ no South African health science university admission criteria favour these students, while some policies (e.g. the national benchmark exam) actually disadvantages them. ${ }^{11}$ Most South African training institutions use colour as a proxy to enable them to meet their transformation agenda, but fail to meet their social responsibilities to train for the needs of the country. This is evident in the small number of graduates working in the public sector, $^{2}$ as well as in the under-representation of rural students in training institutions. ${ }^{12}$ Only $27 \%$ of those studying Medicine,
Physiotherapy, Occupational Therapy or Dentistry at nine South African health science intuitions in 2003 were from rural areas, despite $44 \%$ of the population living in rural areas at that time. ${ }^{12,13}$

All South African universities, including the Nelson R Mandela School of Medicine (NRMSM), University of KwaZulu-Natal (UKZN), have a social responsibility to direct education, research and services that address the priority health concerns of the communities served by its graduates,${ }^{14}$ and to ensure the curriculum, content, context of education and graduate competencies address local health challenges. ${ }^{15}$ The mission statement of the NRMSM commits the institution to 'function holistically, ethically and in a socially responsive manner within the African health care environment. ....16 In the curriculum currently being developed, the NRMSM has committed itself to greater social accountability by training more generalist doctors who are able to meet the needs of patients seeking care at public-sector facilities throughout the province. ${ }^{17,18}$ By limiting the definition of social responsibility only to that of staffing, one might expect to see evidence of UKZN meeting this criterion of social accountability and find a significant number of UKZN graduates working in healthcare facilities in KwaZulu-Natal (KZN) Province and, in particular, at district hospitals (DHs). Little is known, however, about where UKZN graduates have chosen to work, or the impact/contribution that they are making to service delivery in the province, and therefore to what extent the university's mandate has been achieved.

In addition to the role that training institutions should play in ensuring that their graduates are skilled, competent, professional, ethical and able to provide health care to the whole population, there are a number of national, provincial and local initiatives 
that specifically aim to increase the staffing of public healthcare facilities. These include training South African doctors in Cuba; the KZN provincial Department of Health (DoH) bursary programme, which supports students at South African healthcare training institutions; and the Umthombo Youth Development Foundation scholarship scheme (UYDF SS), which selects and supports rural youth to train to become HCPs on the understanding that they will return to work in the district hospital (DH) where they were selected, a year work-back for each year that they have received financial support. ${ }^{19}$ The KZN DoH bursary programme expects its graduates to work at any provincial hospital for a year for each year they have received financial support. In addition, the South African Government, through the National Student Financial Aid Scheme (NSFAS), provides funding to those wanting to access tertiary education whose families earns less than R120 000/year. There is no work-back obligation associated with NSFAS funding, as it is a loan that must be repaid. Little is known about the impact of these initiatives on the staffing levels at DHs in KZN.

The aim of this study was to investigate the extent to which UKZN contributes to the training of HCPs working in DHs in KZN, as well as to determine the funding sources used to train to become an HCP and the impact these initiatives have on staffing at DHs.

\section{Methods}

This observational, descriptive cross-sectional study was conducted at all $37 \mathrm{DH}$ s in KZN, the questionnaire being piloted among interns at Wentworth Hospital. The target population were DHs, government bodies, NGOs responsible for selecting and funding health science students, and UKZN, which has a social responsibility to train for the needs of the community that it serves. The study population comprised all HCPs (doctors, physiotherapists, radiographers, pharmacists, dietitians, dentists and dental therapists) working in DHs in KZN in November 2016. These cadres represent some of the key healthcare staff, with shortages of these personnel often having a major impact on service delivery.

No sampling method was used, as all the HCPs meeting the inclusion criteria working in the $37 \mathrm{DHs}$ in KZN were included. The human resources (HR) department in each hospital was also asked to give numbers for how many HCPs were working at the hospital in November 2016 to enable the returns to be correlated with the number of staff working at that time. Envelopes containing the research questionnaires were distributed to the $\mathrm{DH}$ s through the medical managers and medical students placed at DHs for training. Every HCP who was part of the study population working at a DH in KZN in November 2016 was asked to complete the questionnaire. Completed questionnaires were returned to the research assistant for capturing.

Ethical approval for the study was given by the UKZN Biomedical Research Ethics committee (Ref: BE 330/16). Permission to conduct the study was given by the KZN provisional Department of Health, and each participant signed a consent form after reading the information document.

\section{Results}

Data were obtained from 29 of the 37 (78\%) DHs in KZN and from 22/29 (76\%) HR departments. The HR departments indicated that there were 558 health professionals in the categories of interest working at those 22 hospitals in November 2016 and completed questionnaires were received from $312 \mathrm{HCPs}$, giving a $56 \%$ return from $\mathrm{HCP}$ working at those $\mathrm{DHs}$. Unfortunately data in some questionnaires were missing, resulting in the denominator changing when data are reported.

The results are presented in four sections: demographic data; UKZNs contribution to HCP training of staff at DHs; funding sources for staff at DHs; and associations between UKZN training, funding and working for longer than five years at a $\mathrm{DH}$.

Table 1: Demographic data and years worked at District hospital $(n=506)$

\begin{tabular}{|c|c|c|c|c|c|c|c|}
\hline \multirow{2}{*}{$\begin{array}{l}\text { Category of healthcare } \\
\text { professional }\end{array}$} & \multicolumn{2}{|c|}{ Age in years } & \multicolumn{2}{|c|}{ Gender } & \multicolumn{2}{|c|}{ Years working at a district hospital } & \multirow{2}{*}{$\begin{array}{l}\text { Community service in } 2016 \\
\text { (no.) }\end{array}$} \\
\hline & Age & Number & Male & Female & $<5$ years & $>5$ years & \\
\hline Foreign-qualified doctors $(n=73)^{*}$ & $30+$ & 54 & 37 & 17 & 45 & 9 & \\
\hline South African doctors $(n=153)^{*}$ & $<30$ & 71 & 30 & 41 & 71 & 0 & 46 \\
\hline \multirow[t]{2}{*}{ Pharmacists ( $n=98$ ) } & $<30$ & 59 & 24 & 35 & 59 & 0 & 11 \\
\hline & $30+$ & 39 & $11^{*}$ & $22^{*}$ & 26 & 13 & \\
\hline \multirow[t]{2}{*}{ Radiographers $(n=66)$} & $<30$ & 30 & 8 & 22 & $25^{*}$ & 1 & 11 \\
\hline & $30+$ & 36 & 20 & 16 & 25 & 11 & \\
\hline Physiotherapists ( $n=53$ ) & $<30$ & 34 & 11 & 23 & 34 & 0 & 20 \\
\hline \multirow[t]{2}{*}{ Dietitians ( $n=31$ ) } & $<30$ & 17 & 0 & 17 & $13^{*}$ & $1^{*}$ & 10 \\
\hline & $30+$ & 14 & 3 & 11 & 12 & 2 & \\
\hline \multirow[t]{2}{*}{ Dentists ( $n=19$ ) } & $<30$ & $6^{*}$ & 1 & 5 & 6 & 0 & 6 \\
\hline & $30+$ & 13 & 8 & 5 & 6 & 7 & \\
\hline \multirow[t]{2}{*}{ Dental therapists $(n=13)$} & $<30$ & 13 & 3 & 10 & 13 & 0 & 2 \\
\hline & $30+$ & 0 & 0 & 0 & 0 & 0 & \\
\hline Totals & & 506 & 213 & 277 & $423^{*}$ & $64^{*}$ & 106 \\
\hline (\%) & & & $(43 \%)$ & $(57 \%)$ & $(87 \%)$ & (13\%) & $(22 \%)$ \\
\hline
\end{tabular}

*Some data missing. 


\section{Demographic data}

A total of 514 HCPs from 29 DHs participated in the study, of whom $44 \%$ were doctors, and 19\% were pharmacists (Table 1), $57 \%$ were female and the average age was 42 years. The majority $(82 \%)$ of HCPs working in the DHs in KZN were South African. Foreign qualified HCPs came from: Britain (26; 5\%), Democratic Republic of Congo (DRC) (14; 3\%), Zimbabwe (12; 3\%) and the balance from a number of African and European countries. Just over a third of HCPs working at DHs $(189 / 501 ; 38 \%)$ had qualified since 2013. The vast majority of HCPs working at DHs (423/487; $87 \%)$ had been at the hospital for five years or less, $65 \%$ (250/382) planned to leave in the near future, and 29\% (69/241) planning to leave at the end of 2016.

Of the 226 doctors, the majority were South African (68\%; 153/ 226). Most of the foreign-qualified HCPs were working as doctors, with 26/226 coming from Britain, 14/226 from the DRC, 7/226 from Nigeria, 12/226 from other African countries (Zimbabwe, Eritrea, Swaziland, Botswana, Tunisia, Uganda, Mauritius), 1/226 from America, 8/226 from other European countries and 5/226 from Cuba.

Over half of the South African doctors working at $\mathrm{DH}$ s had graduated from UKZN (see Table 2), with the balance coming from the University of Cape Town $(15 ; 11 \%)$, Walter Sisulu University $(12 ; 9 \%)$, University of Witwatersrand $(9 ; 6 \%)$, Sefako Makgatho University $(7 ; 5 \%)$, University of the Free State $(6 ; 4 \%)$, University of Pretoria ( $5 ; 4 \%)$, Stellenbosch University $(3 ; 2 \%)$, and three $(3 ; 2 \%)$ were Cuban trained. As UKZN does not offer dentistry or radiography, it was not unexpected that none of these health professionals would have trained at UKZN.

Data on funding were completed by only $358 / 514$ (70\%) of the participants and may therefore be skewed. Just over a third of doctors (36\%) self-funded their degrees, this figure being closer to half of all health professionals, with one-fifth being funded by the KZN DoH bursary programme, and only $11 \%$ through NSFAS, the UYDF scholarship programme and other funding programmes (Table 3).

There was no association between training at UKZN and duration of stay longer than five years among doctors, pharmacists, physiotherapists, dietiticans or dental therapists (Table 4). There was also no association between training overseas and remaining at the $\mathrm{DH}$ for more than five years (OR 1.63; $\mathrm{Cl} 0.72-3.68 ; p=0.16$ ), with just under a fifth $(14 / 73 ; 19 \%)$ of the medical doctors who had trained abroad having come to South Africa as part of their training placement programmes, all of whom planned to leave upon completion of their commitment.

Table 2: Training location of the DH healthcare professionals $(\boldsymbol{n}=423)$

\begin{tabular}{lccc}
\hline $\begin{array}{l}\text { All health } \\
\text { professionals }\end{array}$ & $\begin{array}{c}\text { Trained at } \\
\text { UKZN }\end{array}$ & $\begin{array}{c}\text { Trained in rest } \\
\text { of SA }\end{array}$ & $\begin{array}{c}\text { Trained } \\
\text { outside SA }\end{array}$ \\
\hline Doctors $(n=141)$ & 81 & 57 & 3 \\
\hline Pharmacists $(n=98)$ & 61 & 36 & 1 \\
\hline Radiographers $(n=66)$ & 0 & 63 & 3 \\
\hline Physiotherapists $(n=53)$ & 34 & 19 & 0 \\
\hline Dietitians $(n=31)$ & 19 & 12 & 0 \\
\hline Dentists $(n=21)$ & 0 & 21 & 0 \\
\hline Dental therapist $(n=13)$ & 12 & 1 & 0 \\
\hline Total $(\%)$ & $207(49 \%)$ & $209(49 \%)$ & $7(2 \%)$ \\
\hline
\end{tabular}

Table 3: Funding sources of the health professionals $(n=358)$

\begin{tabular}{lccccc}
\hline $\begin{array}{l}\text { Health } \\
\text { professionals }\end{array}$ & Self-funded & $\begin{array}{c}\text { KZN } \\
\text { bursary }\end{array}$ & $\begin{array}{c}\text { NSFAS } \\
\text { loan }\end{array}$ & $\begin{array}{c}\text { UYDF } \\
\text { scholarship }\end{array}$ & Other \\
\hline $\begin{array}{l}\text { South African } \\
\text { doctors }\end{array}$ & 48 & 40 & 10 & 10 & 25 \\
$\begin{array}{l}\text { Pharmacists } \\
\text { Radiographers }\end{array}$ & 25 & 15 & 15 & 8 & 0 \\
$\begin{array}{l}\text { Physiothera- } \\
\text { pists }\end{array}$ & 22 & 7 & 8 & 8 & 3 \\
$\begin{array}{l}\text { Dietitians } \\
\text { Dentists }\end{array}$ & 15 & 3 & 2 & 1 & 3 \\
$\begin{array}{l}\text { Dental thera- } \\
\text { pists }\end{array}$ & 3 & 4 & 2 & 2 & 3 \\
\hline Total (\%) & $156(44 \%)$ & $83(23 \%)$ & $41(11 \%)$ & $38(11 \%)$ & $40(11 \%)$ \\
\hline
\end{tabular}

Table 4: Association between training at UKZN, funding source and duration of stay $>5$ years at $\mathrm{DH}$

\begin{tabular}{|c|c|c|c|c|c|}
\hline $\begin{array}{l}\text { Category } \\
\text { of health } \\
\text { professional }\end{array}$ & $\begin{array}{l}\text { Worked } \\
<5 \text { years } \\
\text { at } \mathrm{DH}\end{array}$ & $\begin{array}{l}\text { Worked } \\
>5 \text { years } \\
\text { at } \mathrm{DH}\end{array}$ & $\mathrm{Cl}$ & $\begin{array}{l}\text { Odds } \\
\text { ratio }\end{array}$ & $p$-value \\
\hline \multicolumn{6}{|c|}{ Trained at UKZN and duration of stay } \\
\hline Doctors $(n=81)$ & 67 & 14 & $0.32-1.7$ & 0.75 & 0.329 \\
\hline Pharmacists $(n=61)$ & 54 & 7 & $0.14-1.37$ & 0.4 & 0.157 \\
\hline $\begin{array}{l}\text { Physiotherapists } \\
(n=34)\end{array}$ & 28 & 6 & $0.25-5.2$ & 1.14 & - \\
\hline Dietitians $(n=19)$ & 18 & 1 & - & - & - \\
\hline $\begin{array}{l}\text { Dental therapists } \\
(n=12)\end{array}$ & 12 & 0 & - & - & - \\
\hline \multicolumn{6}{|c|}{ KZNDOH bursary and duration of stay } \\
\hline Doctors $(n=40)$ & 38 & 2 & $\begin{array}{c}0.036- \\
0.71\end{array}$ & 0.16 & 0.007 \\
\hline Pharmacists $(n=15)$ & 13 & 2 & $0.16-4.05$ & 0.82 & - \\
\hline $\begin{array}{l}\text { Physiotherapists } \\
(n=7)\end{array}$ & 6 & 1 & $0.25-8.6$ & 1.45 & - \\
\hline Dietitians $(n=3)$ & 3 & 0 & - & - & - \\
\hline $\begin{array}{l}\text { Dental therapists } \\
(n=4)\end{array}$ & 4 & 0 & - & - & \\
\hline \multicolumn{6}{|c|}{ NSFAS loan and duration of stay } \\
\hline Doctors $(n=10)$ & 9 & 1 & $0.06-4.05$ & 0.49 & - \\
\hline Pharmacists $(n=15)$ & 12 & 3 & $0.36-5.9$ & 1.43 & - \\
\hline $\begin{array}{l}\text { Physiotherapists } \\
(n=8)\end{array}$ & 6 & 2 & - & - & - \\
\hline Dietitians $(n=2)$ & 1 & 1 & - & - & - \\
\hline $\begin{array}{l}\text { Dental therapists } \\
(n=1)\end{array}$ & 1 & 0 & - & - & - \\
\hline \multicolumn{6}{|c|}{ UYDF scholarship and duration of stay } \\
\hline Doctors $(n=10)$ & 10 & 0 & - & - & - \\
\hline Pharmacists $(n=8)$ & 8 & 0 & - & - & - \\
\hline $\begin{array}{l}\text { Physiotherapists } \\
(n=8)\end{array}$ & 8 & 0 & - & - & - \\
\hline Dietitians $(n=1)$ & 1 & 0 & - & - & - \\
\hline $\begin{array}{l}\text { Dental therapists } \\
(n=4)\end{array}$ & 4 & 0 & - & - & - \\
\hline
\end{tabular}


There was a significant association $(p=0.007)$ between funding from KZN DoH and duration of stay at district hospitals for five years or longer. Doctors funded by the provincial $\mathrm{DOH}$ were 0.84 times less likely to remain at a $\mathrm{DH}$ for more than five years than those funded from other sources. However, there was no association between funding from KZN DoH and duration of stay at district hospitals for five years or longer among pharmacists, physiotherapists, dietitians or dental therapists. There was no association between NSFAS and UYDF funding and duration of stay greater than five years for any of the categories of HCP, as none of the health professionals funded by the latter had worked at the $\mathrm{DH}$ for longer than five years.

Just under half (43\%) of the South African doctors were planning to leave within the next year or two, with specialisation given as the most common reason for their departure. Among the physiotherapists, $73 \%$ (36/49) planned to leave at the end of the year, or after their community service (CS) contract was finished, due a lack of available posts at their current location.

\section{Discussion}

Despite the challenges of gathering good data, this is the first study to explore staffing levels from the perspective of where graduates trained and who paid for the training.

It is interesting to note that $18 \%$ of the HCPs working in district hospitals are foreign trained and that $32 \%$ of doctors working at DHs are trained outside SA. This has important implications for human resource planning, with such a significant proportion of the workforce consisting of foreign-qualified HCPs. For many years medical managers have had challenges in staffing particularly rural district hospitals. Africa Health Placement (AHP), a non-government organisation established in 2005 to help recruit local and foreign HCPs, has to date sourced 2892 doctors for South Africa of whom 1160 have been placed in KwaZulu-Natal. ${ }^{20}$ AHP has concentrated on recruiting foreignqualified doctors in batches to increase the staff numbers at rural $\mathrm{DH}$, as the availability of adequate staffing at these hospitals attracts SA graduates when there is a team to work with and learn from, and where patient health is not compromised.

In addition, since 1996 there have been a number of governmentto-government initiatives to help recruit staff for government hospitals, notably with Cuba, Tunisia and Iran. Training of South African medical students in Cuba was initiated in 2012, with students being chosen from each district in South Africa. Of the 556 doctors who have graduated from this programme, 104 come from $\mathrm{KZN}^{21}$ with the emphasis of the training on primary care and health promotion, ideally preparing graduates to work in community health centres and in DHs. It was disappointing therefore to find only three South African doctors trained in Cuba working in DHs, which may be due to the small number trained to date and incomplete data obtained in this study. Their absence needs to be followed up to determine where these graduates have chosen to work on their return from Cuba, as the PHC clinics and DHs are ideal places for them to apply their knowledge and skills, considering the focus of their training. With 1000 South Africans sent for training in each of 2013, 2014 and 2015 and a total of 2910 students currently training in Cuba this picture may substantially change in the future. ${ }^{21}$

Notwithstanding the current funding crisis and the challenges that new graduates are having to obtain posts in 2017, the South African DoH needs to be clear about the role of foreign-qualified HCPs in the delivery of services. With over $32 \%$ of the DH doctors being foreign qualified, it is clear that this cadre of HCPs play an important role in the provinces' healthcare system. However, these doctors face enormous challenges in obtaining registration with the HPCSA, obtaining work permits and renewing work visas. If foreign doctors do form an integral part of the plan to staff DHs appropriately, then steps need to be put in place to facilitate and expedite their registration with the HPCSA, as well as addressing their work visa issues. In contrast to the doctors, there were very few foreign-trained pharmacists, physiotherapist, radiographers, dentists and dental therapists working in $\mathrm{DHs}$ in KZN.

The results from this study highlight that $22 \%$ of the workforce and $30 \%$ of the South African doctors working at DHs (representing $20 \%$ of the total doctor workforce) were doing their compulsory CS-junior staff who have recently graduated. Consistent with previous findings, many of the South African medical graduates remain for only a relatively short period of time at the $\mathrm{DHs}^{22}$ with $43 \%$ of South African graduates planning to leave at the end of the year or within the next year or so, with specialisation and lack of posts being the commonest reasons given. This high percentage of junior staff, and large workforce turnover, has implications for quality of care and decentralised training programmes envisioned by the UKZN as a means to expand the teaching platform and increase the number of students admitted into the MBChB programme.

It was encouraging to note that $36 \%$ of all doctors working at DHs in KZN graduated from UKZN, suggesting that the institution is fulfilling its mandate to train for its population's needs. With a new emphasis on decentralised clinical training in Port Shepstone, Newcastle, Empangeni and at a variety of $\mathrm{DHs}$, it is anticipated that the content and context of the training in the future will be more relevant to the local settings, which will better prepare graduates for the challenge of working in $\mathrm{DHs}$. However, just under half of these UKZN graduates are CSOs $(37 / 81 ; 46 \%)$, or have been working at a $\mathrm{DH}$ for less than five years $(67 / 81 ; 83 \%)$. There was no association between training at UKZN as a doctor and remaining at a DH for longer than five years, which has important implications for any decentralised training programme. The large number of UKZN graduates may be due to the compulsory nature of CS and the lack of posts in urban settings, rather than a reflection of the content and context of the training provided. With no significant association between training at UKZN and long-term placement at a $\mathrm{DH}$, the university needs to review student selection, and the content and context of its training if it is serious about contributing to the long-term staffing of DHs, as these have been shown to influence where graduates work. 23,24

In addition, UKZN does appear to be playing an important role in meeting its social obligations in training pharmacists (61/98; $62 \%)$, physiotherapists (33/53; 64\%); and dental therapists $(12 / 13 ; 92 \%)$, although there was no association between training at UKZN and long-term work placement at a $\mathrm{DH}$. These $\mathrm{HCPs}$ play an import role in meeting the service delivery needs at DHs.

Despite the current \#Feesmustfall, only $8 \%$ of doctors and $9 \%$ of those who participated in the study had received an NSFAS loan. This needs further investigation, as it may imply that poorer students (those eligible for NSFAS) were unable to study towards a health science degree without additional support above that provided by NSFAS. Targeted financial and educational initiatives have been shown to be effective ways of staffing (rural) district 
hospitals in Australia and SA. ${ }^{10,12}$ Reid highlighted that no admission criteria at any medical school in SA currently favour rural (presumably poor students), ${ }^{11}$ suggesting that universities need to find innovate strategies to recruit and retain rural-origin students if they are serious about meeting their social responsibility to train $\mathrm{HCPs}$ for the needs of the rural population.

Forty (26\%) doctors had received financial support through a KZN DoH bursary, highlighting this important contribution to $\mathrm{DH}$ staffing. Although this initiative appears to be successful in getting doctors to work at $\mathrm{DHs}$, it does not provide long-term staff. The data suggest that doctors with a KZN DoH bursary are less like to remain in $\mathrm{DH}$ s long term than other medical graduates. While the UYDF SS contributed to funding $7 \%$ of doctors, no participant who received such support has worked there for longer than five years, there being no evidence from this study to suggest that this initiative was contributing to the long-term staffing. Among the professional staff other than doctors, the majority were self-funded with KZN provincial bursaries and UYDF playing an important but limited role in the funding of the training of those who have chosen to work at DHs. Neither of these initiatives seem to be making a significant contribution to the long-term staffing of DHs.

Studies from Australia suggest that targeted incentive-based scholarship schemes ${ }^{25}$ contribute to the long-term staffing of rural healthcare facilities. This differs from the findings of this study, with neither the KZN DoH bursary programme nor the UYDF SS being associated with working long term at a $\mathrm{DH}$. However, the success of the cadetship in Australia was linked to mentoring, networking and ongoing postgraduate educational opportunities, factors that are noticeably absent in the South African context.

\section{Limitations}

Despite contacting every $\mathrm{DH}$ in the province and asking the medical managers to encourage all HCP staff to complete the questionnaire, no data were received from eight $\mathrm{DH}$ s and only $56 \%$ of HCPs participated in the study, which may have introduced bias into the findings. The small numbers make the associations unreliable and excellent returns from some larger DHs may have biased some of the findings.

\section{Conclusions}

As UKZN graduates constitute an important, albeit short-term component of the staffing at $\mathrm{DHs}$, the institution must continually review its selection, content and context of training if it is to meet its social responsibility of training for the province's needs. The KZN DoH bursary programme and UYDF scholarship scheme make a small but significant contribution to the staffing of $\mathrm{DH}$ s. It is therefore important to review the role of funding in supporting students who wish to study health science courses, as well as the role of appropriate incentives that might encourage graduates to work long term in $\mathrm{DHs}$.

Disclosure statement - No potential conflict of interest was reported by the authors.

\section{References}

1. Ataguba JE, Mclntyre D. Who benefits from health services in South Africa? Health Econ Policy Law. 2013;8(1):21-46. doi:10.1017/ S1744133112000060
2. George G, Quinlan T, Reardon C. Human Resources for Health: A needs and gaps analysis of HRH in South African. Durban: Durban Health Economics and HIV \& AIDS Research Division (HEARD), University of KwaZulu-Natal;2009.

3. National Department of Health. Human Resources for Health for South Africa 2030. Pretoria: South African National Department of Health; 2011.

4. Hamilton K, Yau J. Global Tug-of-War for Health Care Workers: Migration Policy Institute; 2004. Available from: http://www. migrationpolicy.org/article/global-tug-war-health-care-workers

5. Langa R, Strydom J. The rural health advocacy project 2011 [updated 15 April 2011. Available from: http://www.rhap.org.za/

6. Versteeg M. Rural health fact sheet 2015. Johannesburg: Rural Health Advocacy Project; 2015.

7. Manuel TA, Ramaphosa C, Altman M, et al. National Development Plan 2030. Pretoria: South African Government; 2013.

8. Wilson NW, Couper ID, De Vries E, et al. A critical review of interventions to redress the inequitable distribution of healthcare professionals to rural and remote areas. Rural Remote Health. 2009;9(2):1060.

9. Versteeg M, Couper ID. Position Paper: Rural Health - Key to a Healthy Nation Johannesburg: Rural Health Advocacy Project; 2011. Available from: http://www.rhap.org.za/wp-content/uploads/2011/03/RuralHealth-Key-to-a-Healthy-Nation-RHAP-Position-Paper_March-2011.pdf

10. Ross A, MacGregor G, Campbell L. Review of the Umthombo Youth Development Foundation scholarship scheme, 1999-2013. African Journal of Primary Health Care \& Family Medicine. 2015;7(1): 1-6.

11. Reid SJ, Cakwe M. The contribution of South African curricula to prepare health professionals for working in rural or under-served areas in South Africa: a peer review evaluation. S Afr Med J. 2011;101: 34-8. https://doi.org/10.7196/SAMJ.4526

12. Tumbo JM, Couper ID, Hugo JF. Rural-origin health science students at South African universities. S Afr Med J. 2009;99(1): 54-6.

13. Statistics South Africa. Cencus South Africa 2001. Pretoria: Statistics South Africa; 2001.

14. Boelen $\mathrm{C}$, Je H. Defining and measuring the social accountability of medical schools. Geneva: WHO; 1995.

15. Health Professions Council of South Africa. Core Competencies for Undergraduate Students in the Clinical Associate, Dentistry and Medical Teaching and Learning Programmes in South Africa. Pretoria: HPCSA, Pretoria Health Professions Council of South Africa; 2012.

16. University of KwaZulu-Natal School of Clinical Medicine Vision and Mission. University of Kwazulu Natal College of Health Sciences; 2015 [cited 2016 August 31]. Available from: http://chs.ukzn.ac.za/ Homepage.aspx

17. Slottow R. Community Based Training in a Primary Health Care Model (CBTPHCM). Durban: University of KwaZulu Natal; 2013.

18. Vulindlela! 'Open the Road' - Concept note for a proposed curriculum for the Clinical Years of MBChB at UKZN. Prepared by the Curriculum Development Task Team July 2016. Durban: University of KwaZulu Natal; 2016.

19. MacGregor G. Umthombo Youth Development Foundation Annual report 2014 - 2015. Durban: Durban Umthombo Youth Development Foundation; 2015.

20. Personal communication - unpublished raw data. Africa Health Placements; 2017.

21. Masondo B. South Africans trained in Cuba. Pretoria: National Department of Heath Foreign Workforce Management; 2017.

22. Ross A, Reid S. The retention of community service officers for an additional year at district hospitals in KwaZulu-Natal and the Eastern Cape and Limpopo provinces. S Afr Fam Prac. 2009;51(3): 249-53. https://doi.org/10.1080/20786204.2009.10873856

23. Reid SJ. Pedagogy for rural health. Edu Health (Abingdon). 2011;24(1): 536.

24. Tesson G, Strasser R, Pong RW, Curran V. Advances in rural medical education in three countries: Canada, The United States and Australia. Rural Remote Health. 2005;5(4): 397.

25. Lewis MJ, Ellis R, Adusumilli SK, et al. Twenty-five years on: outcomes of a longitudinal evaluation of the NSW Rural Resident Medical Officer Cadetship Program. Rural Remote Health. 2016;16(3): 1-12. 